\title{
Rifampin in Experimental Endocarditis Due to Staphylococcus aureus in Rabbits
}

\author{
Oto Zak, W. Michael Scheld, and Merle A. Sande
}

\author{
From the Pharmaceuticals Department Research \\ Laboratories, Infectious Diseases, Ciba-Geigy Limited, \\ Basel, Switzerland; Department of Medicine, \\ University of Virginia School of Medicine, \\ Charlottesville, Virginia; Department of Medicine, \\ University of California, San Francisco; and The \\ Medical Service, San Francisco General Hospital, \\ San Francisco, California
}

\begin{abstract}
Rifampin possesses unique activity against Staphylococcus aureus. It is the most active antistaphylococcal antibiotic currently available and has been shown to be particularly effective in eradicating $S$. aureus from abscess cavities in experimental infections. However, resistance develops rapidly in vitro and in vivo when large numbers of organisms $\left(10^{6}-10^{7}\right)$ are present, and use of combination therapy has been recommended. The use of combination therapy is complicated by the finding that in vitro the addition of rifampin may reduce (antagonize) the bactericidal effect of the $\beta$-lactam antibiotics. This study examines the in vivo effect of treatment with a $\beta$-lactam agent (cloxacillin), rifampin, or the combination on the eradication of $S$. aureus from cardiac vegetations in experimental endocarditis. Five different dosage combinations of the $\beta$-lactam agent and rifampin were administered for a three-day period, and an attempt was made to correlate peak serum bactericidal titers with results of quantitative cultures of vegetations after therapy. In two of five regimens the combination of rifampin and cloxacillin produced enhanced efficacy in vivo (synergism); in two regimens the effect was no greater than the effect of either drug alone (indifference), and in one regimen the combination was less effective than either single-drug regimen alone (antagonism). Peak serum bactericidal titers often were predictive of the in vivo effect when high doses of cloxacillin were used but were not consistently predictive of in vivo results when rifampin was the agent responsible for the major therapeutic effect. Rifampin-resistant strains did not emerge in animals receiving combination therapy but were isolated from vegetations from several animals receiving rifampin alone.
\end{abstract}

Staphylococcus aureus is the causative agent of up to $30 \%$ of cases of endocarditis; the frequency of endocarditis due to $S$. aureus is on the rise; and the mortality rate remains high, approaching $40 \%$ [1, 2]. The value of combination antimicrobial therapy in reducing mortality and the usefulness of serum tests for identifying the optimal antibiotic regimens remain controversial [3-5].

Rifampin is the most active antistaphylococcal antibiotic known [6]. However, when a staphylococcal population of $\sim 10^{6}$ bacteria is exposed to rifampin, resistant organisms emerge [7]. For the prevention of emergence of resistant strains in clinical infection, rifampin should be combined with another antistaphylococcal agent. In studies

Please address requests for reprints to Dr. Merle A. Sande, Room 5H22, San Francisco General Hospital, San Francisco, California 94110 of the activity of the combination of rifampin and other antibiotics against $S$. aureus in vitro, divergent results, i.e., synergism, antagonism, and indifference, have been observed [8-10]. In this study we investigated the efficacy of rifampin in combination with cloxacillin at various dosages for the treatment of experimental endocarditis due to $S$. aureus in rabbits and attempted to correlate results with in vitro serum bactericidal titer (SBT).

\section{Materials and Methods}

Production of endocarditis. Left-sided endocarditis was produced in 300 male chinchilla rabbits weighing $\sim 2.5 \mathrm{~kg}$ by methods described previously $[11,12]$. A transaortic valve catheter was inserted into the left ventricle of the heart and retained for the duration of the experiment. Five hours after the placement of the catheter, $10^{5.5}$ 
$10^{6.5} \mathrm{cfu}$ of $S$, aureus were injected iv. The presence of endocarditis was confirmed in all untreated controls by positive quantitative blood cultures $\left(10^{2}-10^{3}\right.$ organisms $\left./ \mathrm{ml}\right) 24 \mathrm{hr}$ after infection and by valve cultures $\left(10^{8}-10^{10}\right.$ organisms $\left./ \mathrm{g}\right)$ at the time of autopsy. Up to $50 \%$ of untreated animals died late on the second day or on the third day of the experiment.

Infecting organism. A penicillinase-producing strain of $S$. aureus (Fitz) was isolated from a patient with endocarditis and was used throughout the study. The MICs were determined by the agardilution technique in Isosensitest agar (Oxoid, London), for inocula of $10^{3}, 10^{5}$, and $10^{7} \mathrm{cfu} / \mathrm{ml}$. The MICs for these inocula were $0.008 \mu \mathrm{g} / \mathrm{ml}$, $0.015 \mu \mathrm{g} / \mathrm{ml}$, and $0.03 \mu \mathrm{g} / \mathrm{ml}$ for rifampin and $0.12 \mu \mathrm{g} / \mathrm{ml}, 0.25 \mu \mathrm{g} / \mathrm{ml}$, and $1.0 \mu \mathrm{g} / \mathrm{ml}$ for cloxacillin, respectively.

Treatment. Water-soluble rifampin sodium salt (Ciba-Geigy, Basel, Switzerland) and cloxacillin sodium salt (Beecham Laboratories, Bristol, Tenn.) were administered alone or in combination. Rifampin was injected iv at dosages of 2,5 , or $20 \mathrm{mg} / \mathrm{kg}$ every $12 \mathrm{hr}$ and cloxacillin, sc at dosages of 60,100 , or $200 \mathrm{mg} / \mathrm{kg}$ every $6 \mathrm{hr}$, administration of each started $24 \mathrm{hr}$ after infection and continued for three days.

Efficacy of therapy. Rabbits were killed by an iv overdose of sodium pentobarbital and were autopsied. Cardiac vegetations were aseptically excised, weighed, suspended in $2 \mathrm{ml}$ of saline, and homogenized in a tissue grinder. The numbers of cfu were determined by serial dilution of the homogenate. For the isolation of rifampin-resistant mutants, pour plates, with brain-heart infusion (BHI) agar with or without $100 \mu \mathrm{g}$ of rifampin $/ \mathrm{ml}$ were used. Results of vegetation titers were compared statistically by the Wilcoxon (Mann-Whitney) rank sum test.

Bactericidal titers and antibiotic concentrations in serum. At the intervals indicated, blood was taken from the ear veins of the treated healthy rabbits or rabbits with endocarditis. The serum was separated and assayed for bactericidal titers and for antibiotic levels. Sera were stored at $-28 \mathrm{C}$ until analysis.

The concentrations of the antibiotics were measured by the agar-well diffusion technique in antibiotic medium no. 1 (Oxoid) with use of Sarcina lutea ATCC $9341\left(10^{7} \mathrm{cfu} / \mathrm{ml}\right)$ as test organism for rifampin and of $S$. aureus K761 $\left(10^{7}\right.$ $\mathrm{cfu} / \mathrm{ml}$ ) for cloxacillin. When the antibiotics were given in combination, a rifampin-resistant mutant of $S$. aureus K761 was used as the test organism for determining the concentration of cloxacillin, whereas rifampin was assayed as described above after inactivation of cloxacillin by the addition of B-lactamase extracted from Bacillus cereus 569/ 119 (Whatman Biochemicals, Springfield Mill, Maidstone, Kent, England) to the serum. Cloxacillin had no effect on the rifampin bioassay. The inhibition zones were determined electronically with a Quantimet 720P (Cambridge Instruments, Cambridge, England), and the regression analysis

Table 1. Concentrations $(\mu \mathrm{g} / \mathrm{ml})$ of rifampin and cloxacillin in plasma of rabbits with endocarditis due to Staphylococcus aureus on the first day of treatment (one rabbit in each group).

\begin{tabular}{|c|c|c|c|c|c|c|c|c|}
\hline \multirow[b]{2}{*}{ Drug or combination (dosage) } & \multicolumn{8}{|c|}{ Indicated time interval after administration (hr) } \\
\hline & $1 / 2$ & 1 & 2 & 3 & 4 & 6 & 8 & 12 \\
\hline Cloxacillin $(200 \mathrm{mg} / \mathrm{kg})$ & 34.2 & 30.6 & 18.1 & 16.3 & 12.1 & 6.8 & $\ldots$ & $\ldots$ \\
\hline Cloxacillin $(100 \mathrm{mg} / \mathrm{kg})$ & 19.2 & 14.1 & 13.6 & 11.6 & 5.9 & 0 & $\ldots$ & $\ldots$ \\
\hline Rifampin $(2 \mathrm{mg} / \mathrm{kg})$ & 1.8 & 1.1 & 0.8 & 0.5 & 0.4 & 0.2 & 0.2 & 0.2 \\
\hline Rifampin $(5 \mathrm{mg} / \mathrm{kg})$ & 7.6 & 5.2 & 4.8 & 3.1 & 2.4 & 1.6 & 1.4 & 0.8 \\
\hline Rifampin $(20 \mathrm{mg} / \mathrm{kg})$ & 37.6 & 26.9 & 22.5 & 19.3 & 17.3 & 15.2 & 10.8 & 7.5 \\
\hline $\begin{array}{c}\text { Cloxacillin }(100 \mathrm{mg} / \mathrm{kg}) \\
\text { plus }\end{array}$ & 13.5 & 11.1 & 12.7 & 10.9 & 9.8 & 7.2 & $\cdots$ & $\ldots$ \\
\hline Rifampin $(2 \mathrm{mg} / \mathrm{kg})$ & 5.9 & 3.9 & 2.2 & 1.4 & 1.2 & 1.0 & 0.7 & 0.3 \\
\hline $\begin{array}{c}\text { Cloxacillin }(100 \mathrm{mg} / \mathrm{kg}) \\
\text { plus }\end{array}$ & 18.6 & 13.8 & 14.0 & 16.6 & 7.1 & 2.1 & $\ldots$ & $\ldots$ \\
\hline Rifampin $(5 \mathrm{mg} / \mathrm{kg})$ & 15.3 & 10.8 & 7.4 & 7.5 & 5.1 & 1.3 & 1.0 & 0.4 \\
\hline $\begin{array}{c}\text { Cloxacillin }(100 \mathrm{mg} / \mathrm{kg}) \\
\text { plus }\end{array}$ & 26.1 & 19.8 & 19.5 & 13.9 & 13.1 & 6.5 & $\ldots$ & $\ldots$ \\
\hline Rifampin $(20 \mathrm{mg} / \mathrm{kg})$ & 37.3 & 24.5 & 22.7 & 17.1 & 18.6 & 11.1 & 8.9 & 4.3 \\
\hline
\end{tabular}




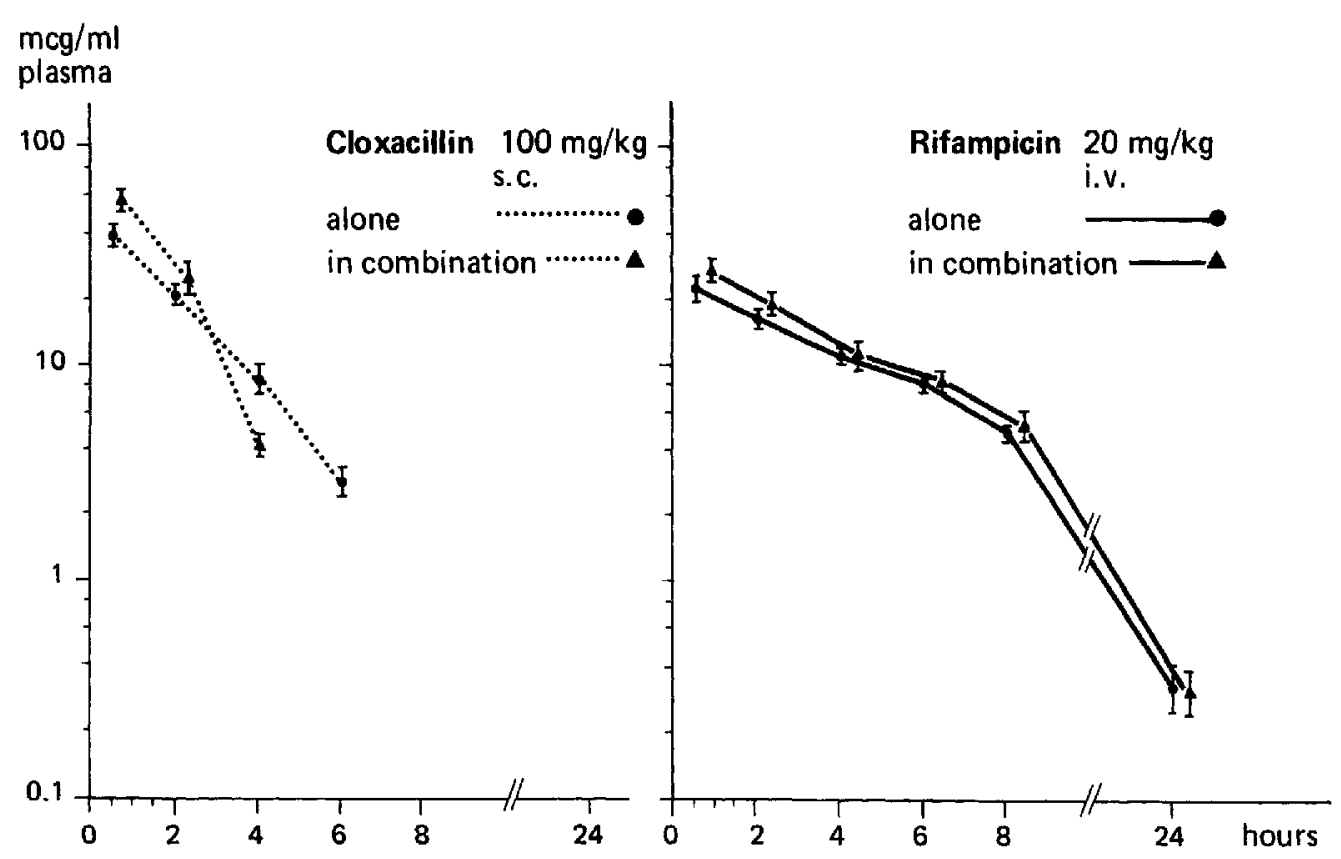

Figure 1. Concentrations of antibiotic in plasma of healthy rabbits $(n=4-8)$ after a single dose of rifampin (rifampicin), cloxacillin, or the combination. Vertical bars indicate SD.

of the standard was performed with the aid of a computer program (Hewlitt Packard 9815, Palo Alto, Calif.).

For both drugs peak SBTs were determined according to the method of Pien et al. [13] on serum drawn $1 \mathrm{hr}$ after administration of antibiotic. Serial twofold dilutions were performed in tubes containing $0.5 \mathrm{ml}$ of pooled horse serum inactivated at $56 \mathrm{C}$ for $30 \mathrm{~min} ; 0.5 \mathrm{ml}$ of a $10^{-3}$ dilution of an overnight culture of $S$. aureus strain Fitz in BHI agar was added to each tube. After $24 \mathrm{hr}$ of incubation at $37 \mathrm{C}, 0.02 \mathrm{ml}$ of each culture free of visible growth was plated onto the surface of a blood agar plate and incubated for $24 \mathrm{hr}$ at $37 \mathrm{C}$. The lowest dilution of serum yielding $\leqslant 10$ colonies was designated the SBT.

\section{Results}

In the pharmacokinetic studies, cloxacillin was administered at two dosages $(100$ or $200 \mathrm{mg} / \mathrm{kg}$ every $6 \mathrm{hr} \mathrm{sc}$ ). Both drug schedules produced peak drug concentrations in the serum similar to those considered therapeutic in humans $(15-30 \mu \mathrm{g} / \mathrm{ml} 1$ hr after administration) (table 1). Rifampin was administered at three different dosages: (l) 2 $\mathrm{mg} / \mathrm{kg}$ every $12 \mathrm{hr}$, which produced very low peak drug concentrations in the serum $(1.1 \mu \mathrm{g} / \mathrm{ml})$ after administration; (2) $5 \mathrm{mg} / \mathrm{kg}$ every $12 \mathrm{hr}$, which produced peak drug concentrations in the serum similar to those achieved in humans after an oral dose of $300 \mathrm{mg}(5.2 \mu \mathrm{g} / \mathrm{ml})$; and (3) $20 \mathrm{mg} / \mathrm{kg}$ every $12 \mathrm{hr}$, which produced peak serum concentrations five times those usually achieved in humans $(26.9 \mu \mathrm{g} / \mathrm{ml})$ (table 1). Administration of the drugs in combination produced drug concentrations in the serum similar to those observed when the agents were administered individually but only when the rifampin dosage was high (20 $\mathrm{mg} / \mathrm{kg}$ ) (figure 1). When the low dosage of rifampin $(2 \mathrm{mg} / \mathrm{kg})$ was given in combination with cloxacillin $(100 \mathrm{mg} / \mathrm{kg})$, concentrations of both drugs in the serum were higher than those observed when the agents were administered individually (table 1 and figure 2).

Results of therapeutic trials revealed that very low dosages of rifampin $(2 \mathrm{mg} / \mathrm{kg}$ ) were effective in reducing vegetation titers when compared with controls $(P<.01)$ but were significantly less effective than cloxacillin $(100 \mathrm{mg} / \mathrm{kg})$ alone $(P<.01)$ (table 2 and figure 3). Rifampin-resistant strains emerged in the vegetations in two of 13 animals 


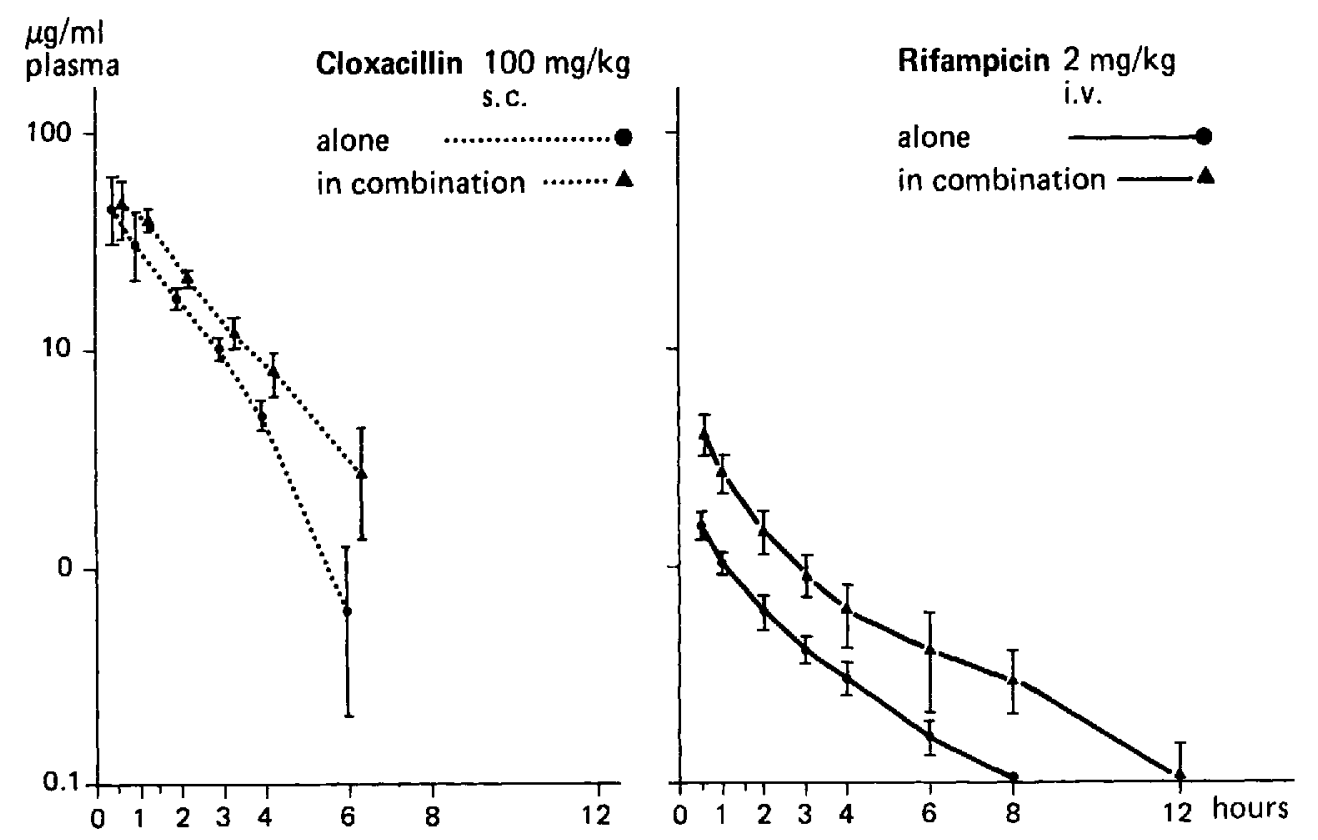

Figure 2. Concentrations of antibiotic in plasma of rabbits $(n=2-7)$ with endocarditis due to Staphylococcus aureus after a single dose of rifampin (rifampicin), cloxacillin, or the combination. Vertical bars indicate SD.

treated with rifampin alone. Combination therapy was likewise less effective than therapy with cloxacillin alone $(P<.01)$, and rifampin-resistant strains did not emerge. Peak SBTs were predictive of the relative efficacy of the three regimens in vitro (figure 4). The median SBT of the sera taken from animals treated with cloxacillin alone was 1:64 compared with 1:8 for the combination of cloxacillin plus rifampin and 1:4 for rifampin alone.

With a higher dosage of rifampin $(5 \mathrm{mg} / \mathrm{kg}$ every $12 \mathrm{hr}$ ), no differences in efficacy were noted between the group treated with the combination and the group treated with cloxacillin $(100 \mathrm{mg} / \mathrm{kg})$ alone (figure 5); the median SBT was 1:64 for cloxacillin alone and 1:32 for the combination (figure 6). Rifampin alone at this dosage was no more effective than it was at the lower dosage ( 2 $\mathrm{mg} / \mathrm{kg}$ ). The mean vegetation titer was $\log _{10} 6.0$ $\mathrm{cfu} / \mathrm{g}$ for both dosages even though the median SBTs were 1:16 with the higher dosage compared with 1:4 with the lower dosage. In one of the animals treated with rifampin $(5 \mathrm{mg} / \mathrm{kg})$ alone, a single rifampin-resistant isolate emerged.

When very high dosages of rifampin were administered $(20 \mathrm{mg} / \mathrm{kg})$, the combination reduced vegetation titers more than did cloxacillin $(100$ $\mathrm{mg} / \mathrm{kg})$ alone $(P=.05)$; and in eight of 17 animals the vegetations were sterile (no growth from culture of total vegetation) compared with four of

Table 2. Efficacy of rifampin (iv) and cloxacillin (sc) alone or in combination in reducing the number of cfu in cardiac valve vegetations in rabbits with experimental endocarditis due to Staphylococcus aureus.

\begin{tabular}{lcccc}
\hline $\begin{array}{l}\text { Dosage of cloxacillin } \\
(\mathrm{mg} / \mathrm{kg} \text { every } 6 \mathrm{hr})\end{array}$ & 0 & $\begin{array}{c}\text { No. of cfu }\left(\log _{10} \pm \mathrm{sE}\right) / \mathrm{g} \text { of vegetation for indicated } \\
\text { dosage of rifampin }(\mathrm{mg} / \mathrm{kg} \text { every } 12 \mathrm{hr})\end{array}$ \\
\hline 0 & $9.56 \pm 0.12$ & $5.9 \pm 0.65$ & 5 & 20 \\
60 & $5.66 \pm 0.25$ & $\mathrm{NE}$ & $6.04 \pm 0.31$ & $5.33 \pm 0.31$ \\
100 & $3.18 \pm 0.46$ & $4.77 \pm 0.24$ & $3.29 \pm 0.26$ & $4.70 \pm 0.29$ \\
200 & $2.46 \pm 0.69$ & 2.0 & $\mathrm{NE}$ & $1.93 \pm 0.47$ \\
\hline
\end{tabular}

NOTE. Antibiotics were administered for three days starting $24 \mathrm{hr}$ after initiation of infection. Determinations of cfu were made 18-24 hr after the last dose of rifampin. $\mathrm{NE}=$ not examined. 


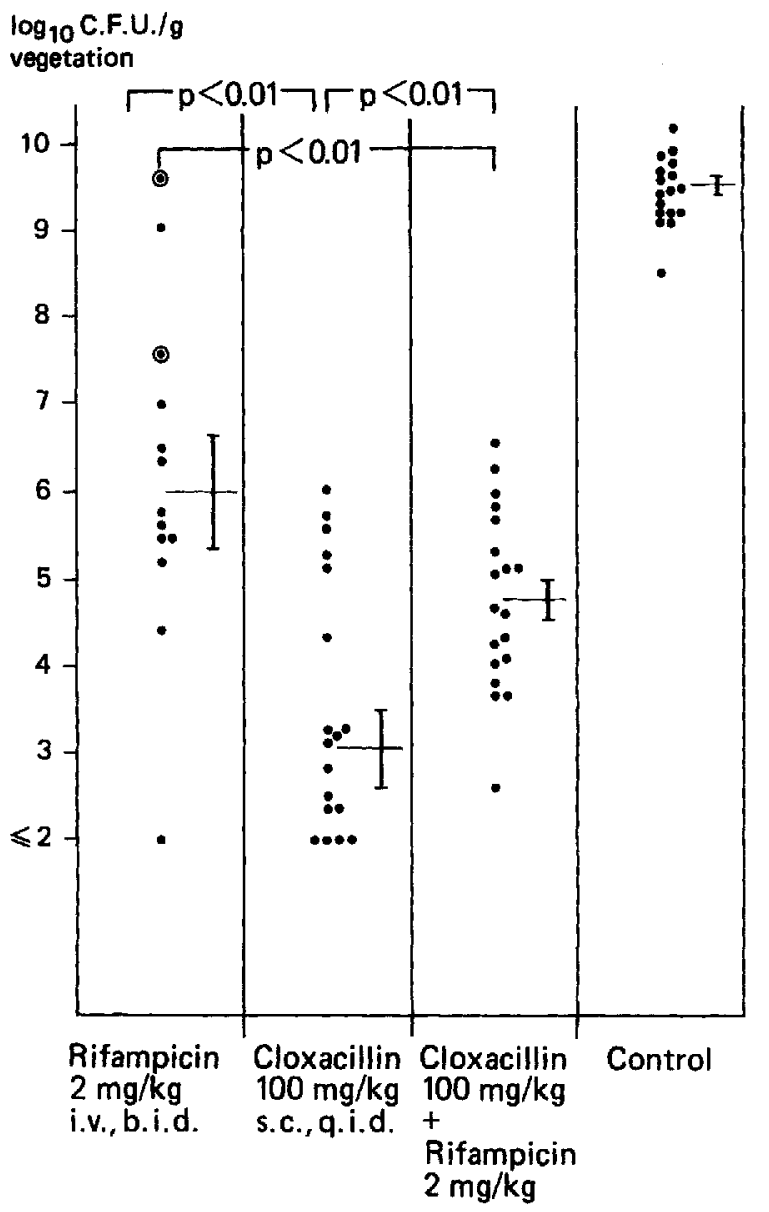

Figure 3. Efficacy of rifampin (rifampicin), cloxacillin, or the combination in reducing bacterial titers in cardiac vegetations in rabbits with experimental endocarditis due to Staphylococcus aureus. Each dot represents the number of viable $S$. aureus found in vegetation of one animal. Horizontal line and vertical bar indicate the mean and SE, respectively. $O=$ rifampin-resistant organisms; b.i.d. $=$ every $12 \mathrm{hr}$; and q.i.d. = every $6 \mathrm{hr}$.

18 animals treated with cloxacillin alone (figure 7). SBTs were predictive of this difference: the median titer for the combination was $1: 128 \mathrm{com}$ pared with 1:64 for cloxacillin alone (figure 8). Rifampin alone at this dosage was less effective than cloxacillin alone or the combination and was not more effective than the rifampin regimens of $2 \mathrm{mg} / \mathrm{kg}$ and $5 \mathrm{mg} / \mathrm{kg}$, although rifampin-resistant strains did not emerge.

Two additional dosage regimens were tested in an attempt to delineate better the pattern demonstrated in the initial studies. When very low dosages of rifampin were used $(2 \mathrm{mg} / \mathrm{kg}$ every 12

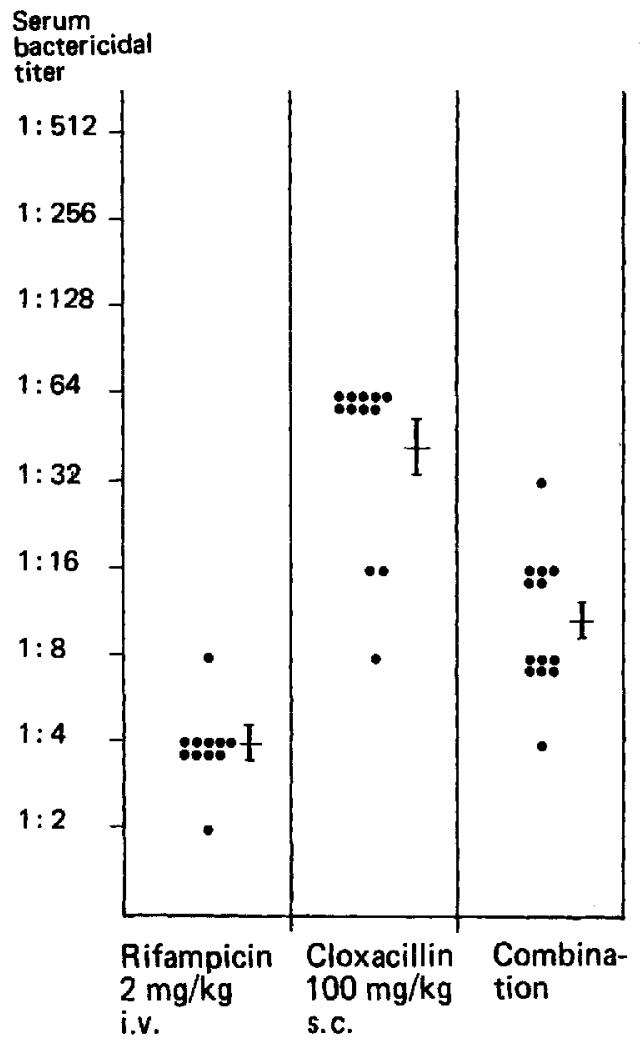

Figure 4. Serum bactericidal titers in rabbits with endocarditis due to Staphylococcus aureus $1 \mathrm{hr}$ after treatment with rifampin (rifampicin), cloxacillin, or the combination. Each dot represents the finding in one animal. Horizontal line and vertical bar indicate the mean and SE, respectively.

hr) but the cloxacillin dosage was doubled (200 $\mathrm{mg} / \mathrm{kg}$ every $6 \mathrm{hr}$ ), the combination proved more effective than cloxacillin alone in reducing vegetation titers $(P<.03)$ and sterilized seven of eight vegetations compared with three of eight vegetations from animals treated with cloxacillin alone (figure 9). These differences were not predicted by SBTs (figure 10). Both cloxacillin alone and the combination produced median peak SBTs of 1:64. The $200-\mathrm{mg} / \mathrm{kg}$ dosage of cloxacillin alone was no more effective than the $100-\mathrm{mg} / \mathrm{kg}$ dosage in reducing vegetation titers $\left(\log _{10} 4.0 \mathrm{cfu} / \mathrm{g}\right.$ vs. $\log _{10}$ $3.1 \mathrm{cfu} / \mathrm{g}$, respectively).

On the other hand, when the very high dosage of rifampin $(20 \mathrm{mg} / \mathrm{kg})$ was combined with a lower dosage of cloxacillin $(60 \mathrm{mg} / \mathrm{kg})$, the combination was more effective than cloxacillin alone $(P<.03)$ (figure 11$)$ but not more effective than 


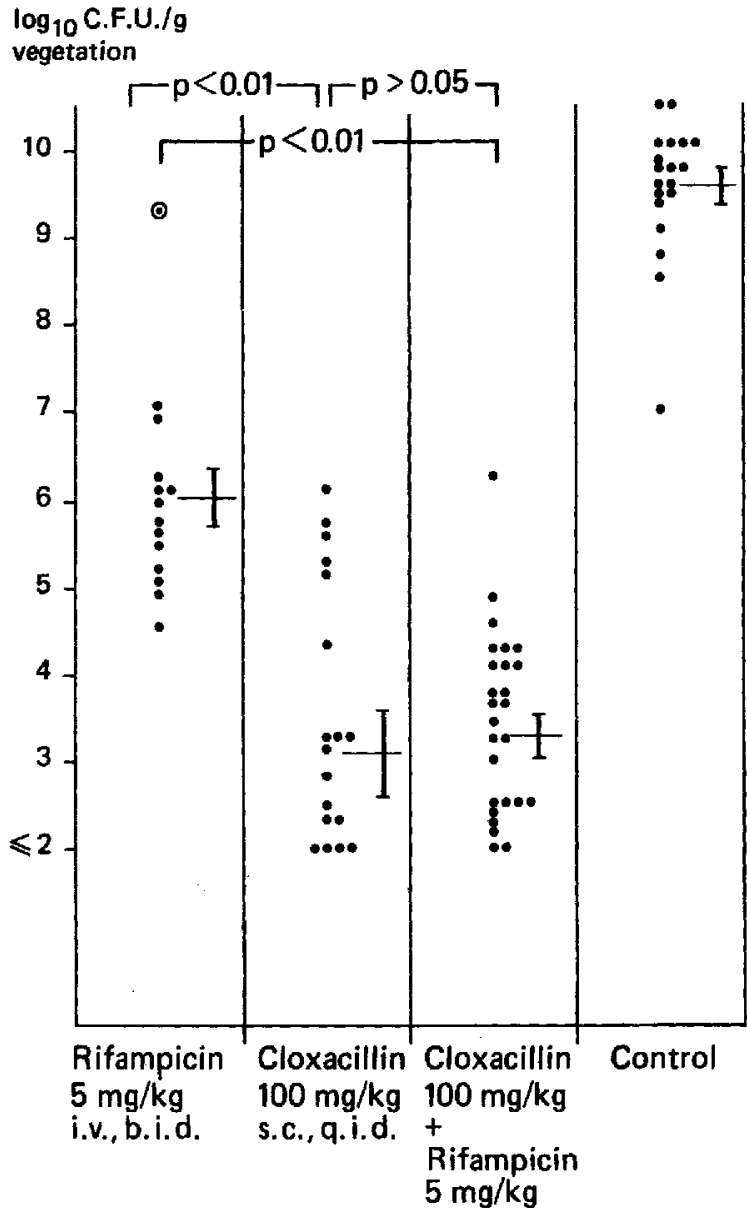

Figure 5. Efficacy of rifampin (rifampicin), cloxacillin, or the combination in reducing bacterial titers in cardiac valve vegetation in rabbits with experimental endocarditis due to Staphylococcus aureus. Each dot represents number of viable $S$. aureus found in vegetation of one animal. Horizontal line and vertical bar indicate the mean and $\mathrm{SE}$, respectively. $\mathrm{O}=$ rifampin-resistant organisms; b.i.d. $=$ every $12 \mathrm{hr}$; and q.i.d. = every $6 \mathrm{hr}$.

rifampin alone $(P>.05)$. These therapeutic results were predicted by the SBTs (figure 12). The median peak SBTs for the high dosage of rifampin $(20 \mathrm{mg} / \mathrm{kg})$ and the combination were both 1:64 compared with 1:16 for the low dosage of cloxacillin alone. Neither of these regimens was as effective as the higher dosages of cloxacillin (100 $\mathrm{mg} / \mathrm{kg}$ or $200 \mathrm{mg} / \mathrm{kg}$ ) alone.

\section{Discussion}

These studies reveal that the addition of rifampin to a $\beta$-lactam antibiotic for the therapy of experi-

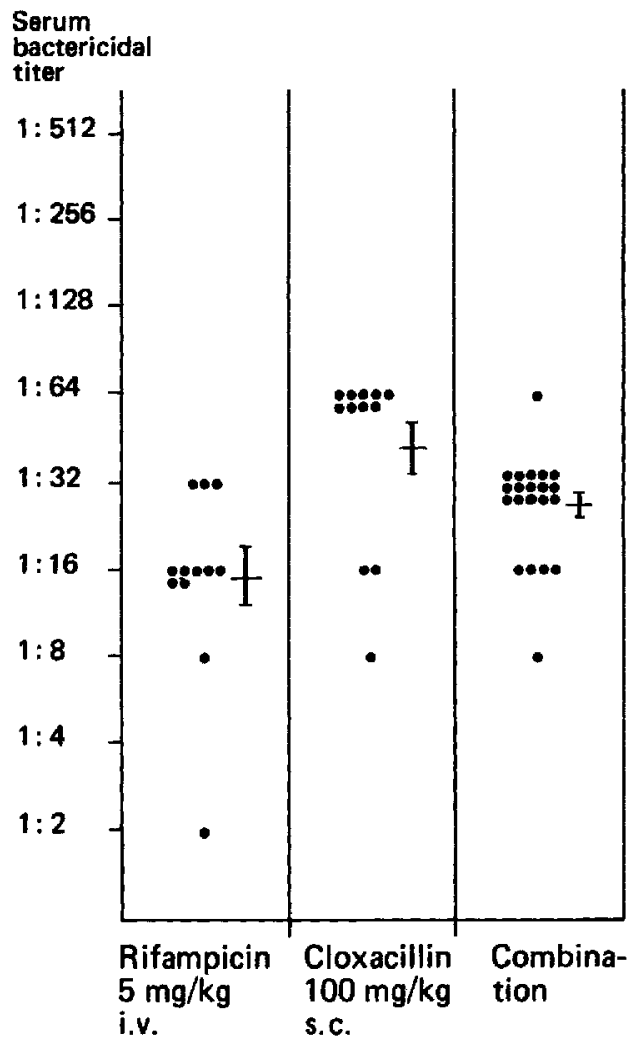

Figure 6. Serum bactericidal titers in rabbits with endocarditis due to Staphylococcus aureus $1 \mathrm{hr}$ after treatment with rifampin (rifampicin), cloxacillin, or the combination. Each dot represents the finding in one animal. Horizontal line and vertical bar indicate the mean and SE, respectively.

mental staphylococcal endocarditis produced a variable effect on the rate at which the cardiac vegetations were sterilized. When the dosage of the $\beta$-lactam agent alone was increased from 60 to 100 to $200 \mathrm{mg} / \mathrm{kg}$ every $6 \mathrm{hr}$, a maximal rate of sterilization was reached at the $100-\mathrm{mg} / \mathrm{kg}$ dosage. However, the addition of very low dosages of rifampin $(2 \mathrm{mg} / \mathrm{kg})$ to this regimen decreased the efficacy of the $100-\mathrm{mg} / \mathrm{kg}$ dosage of cloxacillin but increased the efficacy of the $200-\mathrm{mg} / \mathrm{kg}$ dose. Rifampin alone in all three dosages was much less effective in reducing vegetation titers than was cloxacillin alone. The most effective therapy tested was the combination of the highest dosage of rifampin $(20 \mathrm{mg} / \mathrm{kg})$ plus cloxacillin $(100$ $\mathrm{mg} / \mathrm{kg}$ ). Overall, the addition of rifampin was beneficial in three of the five regimens tested, did not effect the rate of sterilization produced by the 


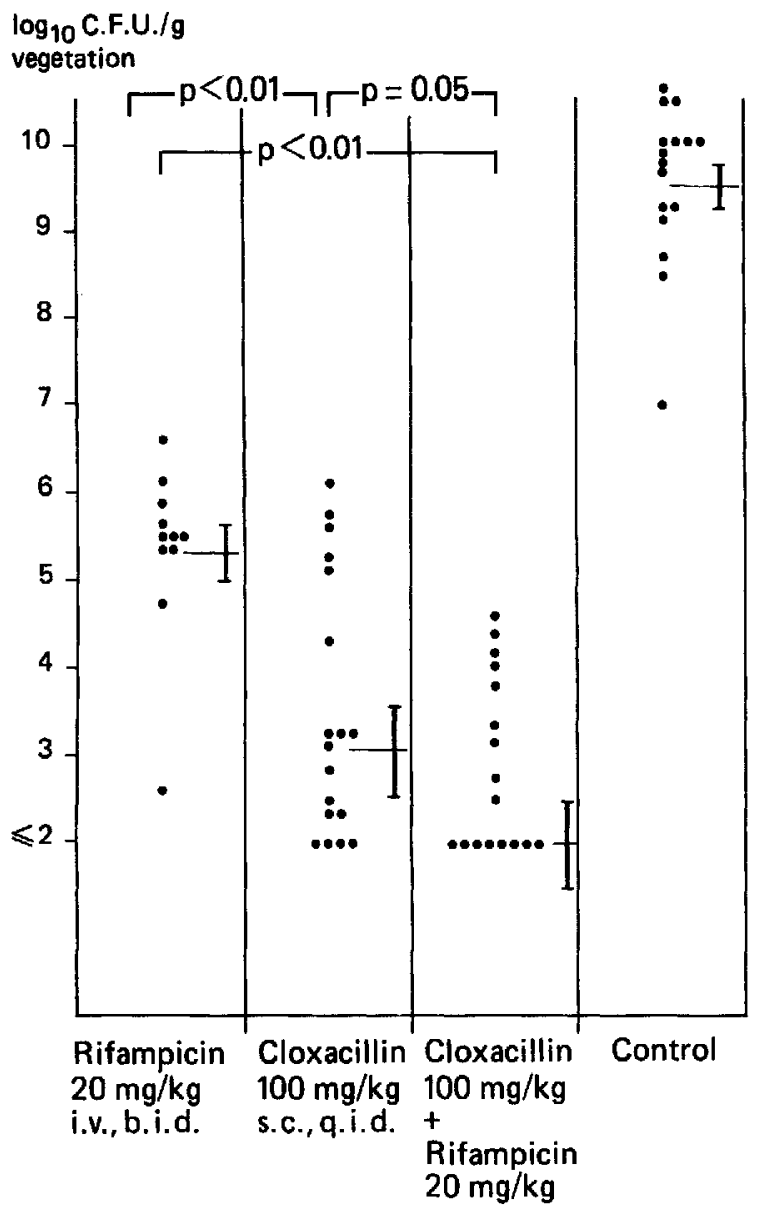

Figure 7. Efficacy of rifampin (rifampicin), cloxacillin, or the combination in reducing bacterial titers in cardiac valve vegetation in rabbits with experimental endocarditis due to Staphylococcus aureus. Each dot represents the number of viable $S$. aureus found in vegetation of one animal. Horizontal line and vertical bar indicate the mean and SE, respectively. Abbreviations: b.i.d. = every $12 \mathrm{hr}$ and q.i.d. = every $6 \mathrm{hr}$.

$\beta$-lactam agent in one regimen, and reduced the effectiveness of the $\beta$-lactam agent in the other regimen.

Whereas peak SBTs usually were predictive of the contribution made by the addition of rifampin to the $\beta$-lactam agent in influencing the rate of sterilization of cardiac vegetations in vivo, the relationship was not consistent. When very low dosages of rifampin were used in addition to an effective dosage of cloxacillin $(100 \mathrm{mg} / \mathrm{kg})$, they reduced both the median peak SBT and the effectiveness of the regimen. When high dosages of rifampin $(20 \mathrm{mg} / \mathrm{kg})$ were added, the increase in

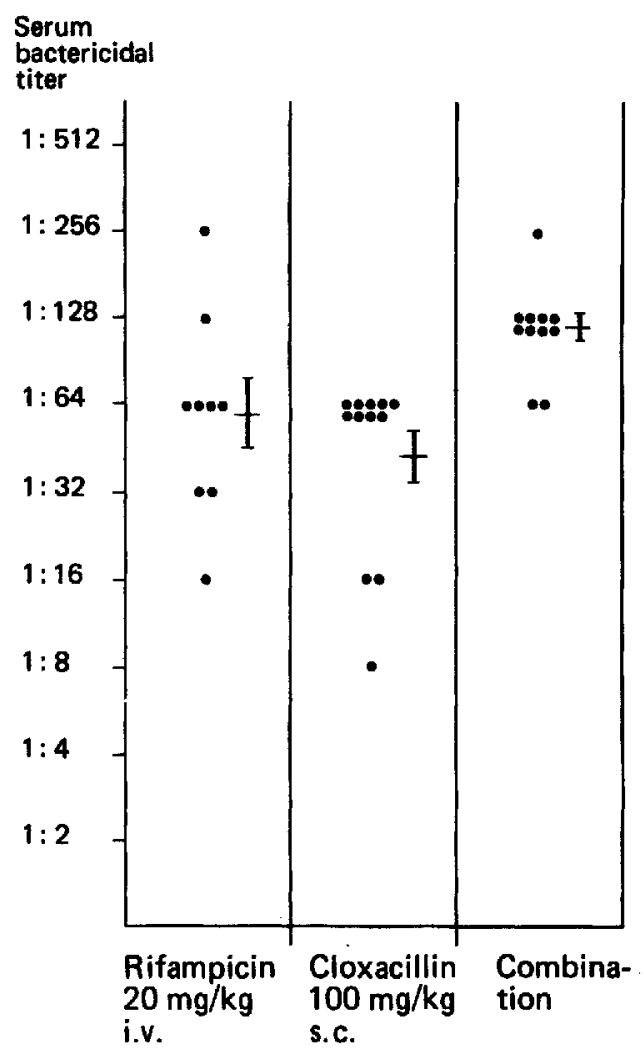

Figure 8. Serum bactericidal titers in rabbits with endocarditis due to Staphylococcus aureus $1 \mathrm{hr}$ after treatment with rifampin (rifampicin), cloxacillin, or the combination. Each dot represents the finding in one animal. Horizontal line and vertical bar indicate the mean and SE, respectively.

SBTs correlated with the increase in effectiveness. The $5-\mathrm{mg} / \mathrm{kg}$ dosage of rifampin decreased SBTs slightly (by one dilution) but did not reduce effectiveness. In general SBTs correlated with the therapeutic efficacy of combination therapy as long as effective dosages of cloxacillin were used.

Although peak SBTs correlated with therapeutic efficacy in rabbits treated with cloxacillin alone, SBTs failed to predict the poor efficacy of rifampin alone. Even though peak titers were 1:16 and 1:64 with the two higher dosages of rifampin $(5 \mathrm{mg} / \mathrm{kg}$ and $20 \mathrm{mg} / \mathrm{kg}$ ), vegetation titers remained high with three days of therapy. The poor efficacy of rifampin given at high dosage combined with the low, ineffective dosages of cloxacillin was also not predicted by the peak SBT. Thus, it appears that, while the influence of rifampin on effective cloxacillin therapy usually was predicted 


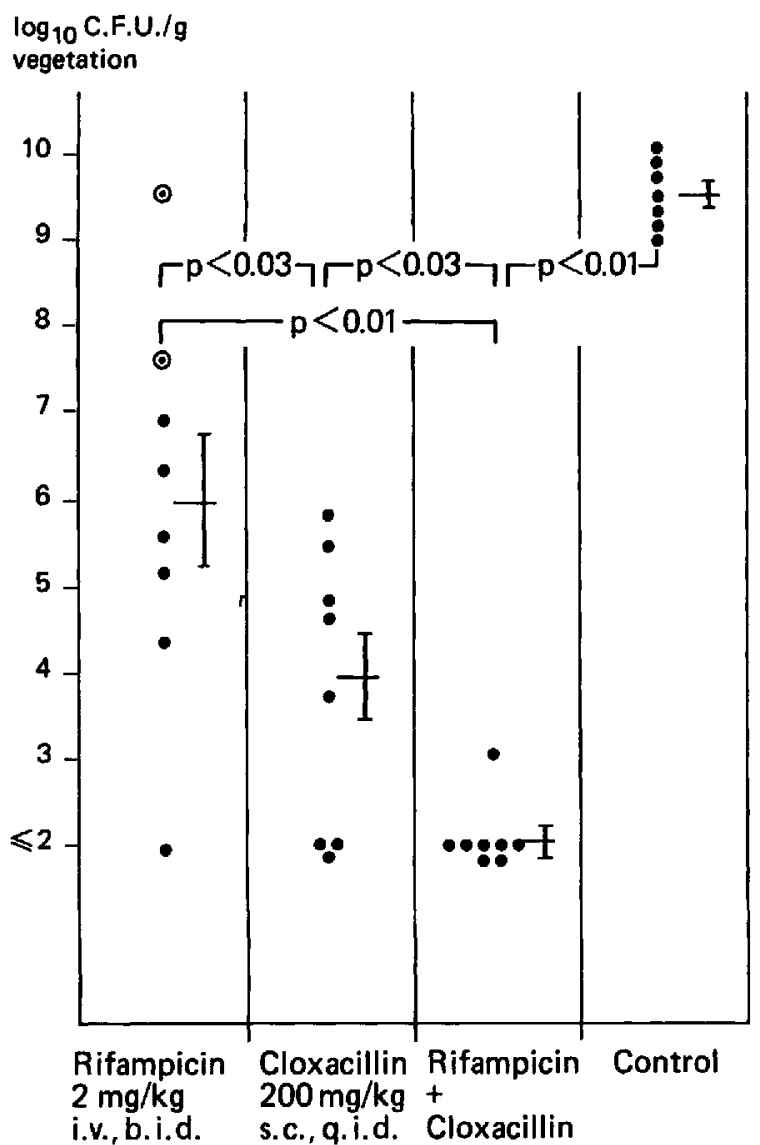

Figure 9. Efficacy of rifampin (rifampicin), cloxacillin, or the combination in reducing bacterial titers in cardiac valve vegetation in rabbits with experimental endocarditis due to Staphylococcus aureus. Each dot represents the number of viable $S$. aureus found in vegetation of one animal. Horizontal line and vertical bar indicate the mean and SD, respectively. $\odot=$ rifampin-resistant organisms; b.i.d. = every $12 \mathrm{hr}$; and q.i.d. = every $6 \mathrm{hr}$.

by the SBTs, the reverse was not the case. The high SBT (1:64) achieved with rifampin alone at high dosage was not altered by low dosages of cloxacillin, and the poor efficacy was not predicted.

The potential beneficial role of rifampin in the treatment of staphylococcal endocarditis most likely will be in the treatment of myocardial or metastatic abscesses and not in the reduction of bacterial titers in vegetations. These studies show that the effect on the rate of elimination of bacteria from vegetations is variable. Earlier studies in vitro have demonstrated the unique ability of this highly lipid-soluble drug to penetrate into phagocytic cells and to kill intracellular orga-

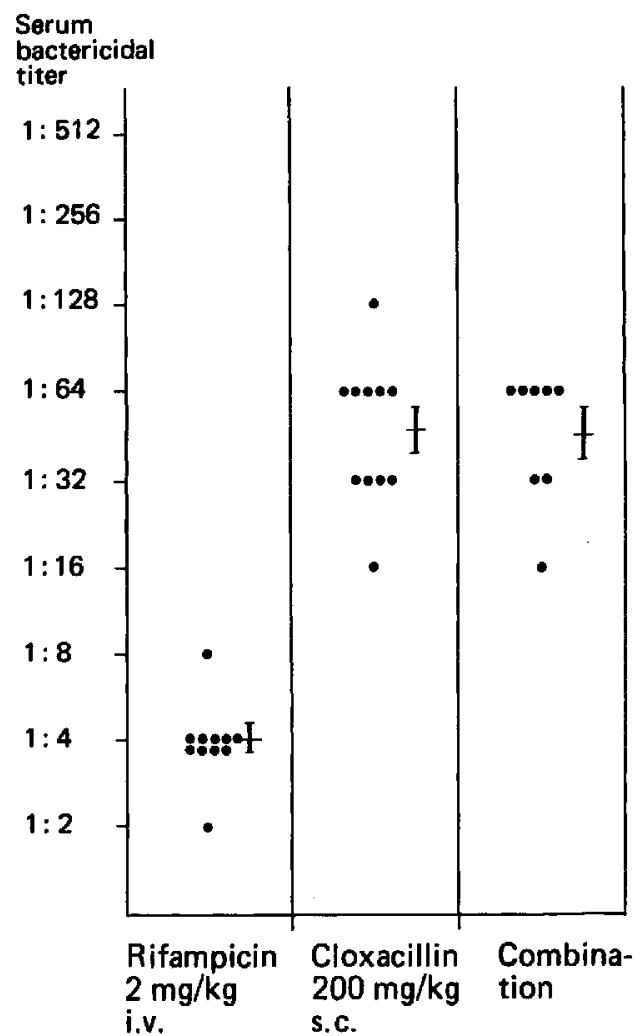

Figure 10. Serum bactericidal titers in rabbits with endocarditis due to Staphylococcus aureus $1 \mathrm{hr}$ after treatment with rifampin (rifampicin), cloxacillin, or the combination. Each dot represents the finding in one animal. Horizontal line and vertical bar indicate the mean and $\mathrm{SE}$, respectively.

nisms. In studies conducted with animals, rifampin was more effective in sterilizing experimental abscesses than were other available antistaphylococcal drugs [14]. Since the mortality from staphylococcal endocarditis frequently is due to the destructive effects of disseminated abscesses in the myocardium, brain, and other vital organs, rifampin may prove to be a valuable adjunct to therapy. Its value, however, would be substantially diminished if the drug consistently decreased the effectiveness of conventional therapy with $\beta$ lactam agents in reducing vegetation bacterial titers. Results of this study indicate that, in fact, the addition of rifampin accelerated the rate at which vegetations were sterilized more frequently than it reduced the rate, and serum SBTs would usually be predictive of the response.

A rational therapeutic strategy for the treatment of staphylococcal endocarditis might therefore 


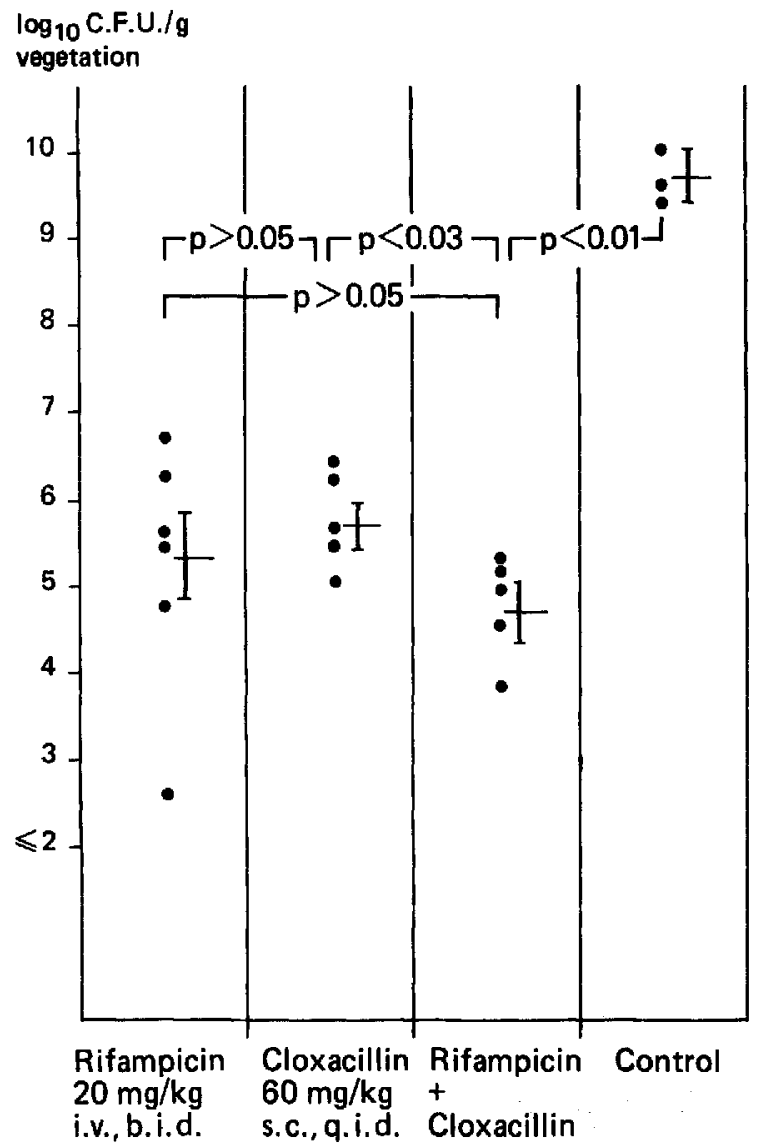

Figure 11. Efficacy of rifampin (rifampicin), cloxacillin, or the combination in reducing bacterial titers in cardiac valve vegetation in rabbits with experimental endocarditis due to Staphylococcus aureus. Each dot represents the number of viable $S$. aureus found in vegetation of one animal. Horizontal line and vertical bar indicate the mean and SE, respectively. Abbreviations: b.i.d. = every $12 \mathrm{hr}$ and q.i.d. $=$ every $6 \mathrm{hr}$.

include initial therapy with a $\beta$-lactam agent alone or in combination with an aminoglycoside. This regimen should quickly reduce vegetation titers and, ideally, effect the most rapid elimination of the organism from the vegetations. If evidence of the formation of a metastatic abscess develops or if a myocardial abscess is detected, addition of rifampin would seem justified [3]. It is important to emphasize that such studies with patients have not been performed, and whereas the addition of rifampin may prove beneficial, surgical drainage, when possible, usually will prove necessary. Measurements of peak SBTs may prove to be of value in predicting the effect on vegetation sterilization, but these should not be expected to pre-

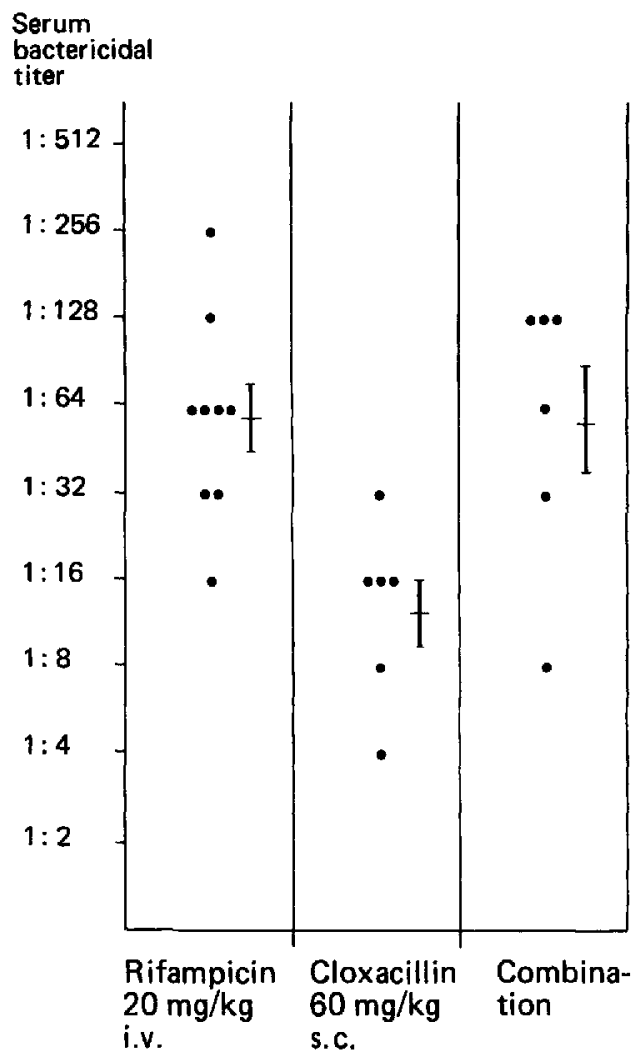

Figure 12. Serum bactericidal titers in rabbits with endocarditis due to Staphylococcus aureus $1 \mathrm{hr}$ after treatment with rifampin (rifampicin), cloxacillin, or the combination. Each dot represents the finding in one animal. Horizontal line and vertical bar indicate the mean and $\mathrm{SE}$, respectively.

dict the effectiveness of the drug combination in abscess cavities.

It is reassuring that in these studies combination therapy did prove effective in preventing the emergence of rifampin-resistant strains, an event observed in $\sim 10 \%$ of the animals treated with rifampin alone.

\section{References}

1. Watanakunakorn C, Tan JS, Phair JP. Some salient features of Staphylococcus aureus endocarditis. Am J Med 1973;54:473-81

2. Neu HC. Endocarditis: the problems remain and multiply. Infection 1979;7:52-3

3. Sande MA, Scheld WM. Combination antibiotic therapy of bacterial endocarditis. Ann Intern Med 1980;92: $390-5$

4. Korzeniowski O, Sande MA, the National Collaborative 
Endocarditis Study Group. Combination antimicrobial therapy for Staphylococcus aureus endocarditis in patients addicted to parenteral drugs and in nonaddicts. Ann Intern Med 1982;97:496-503

5. Coleman DL, Horwitz RI, Andriole VT. Association between serum inhibitory and bactericidal concentrations and therapeutic outcome in bacterial endocarditis. Am J Med 1982;73:260-7

6. Sabath LD, Garner C, Wilcox C, Finland M. Susceptibility of Staphylcoccus aureus and Staphylococcus epidermidis to 65 antibiotics. Antimicrob Agents Chemother 1976;9:962-9

7. Wehrle W. Rifampin: mechanisms of action and resistance. Rev Infect Dis 1983;5(Suppl 3):S407-11

8. Harvey RJ. Antagonistic interaction of rifampicin and trimethoprim. J Antimicrob Chemother 1978;4:315-27

9. Zinner SH, Lagast H, Klastersky J. Antistaphylococcal activity of rifampin with other antibiotics. J Infect Dis 1981;144:365-71
10. Watanakunakorn C, Guerriero JC. Interaction between vancomycin and rifampin against Staphylococcus aureus. Antimicrob Agents Chemother 1981;19:1089-91

11. Scheld WM, Zak O, Vosbeck K, Sande MA. Bacterial adhesion in the pathogenesis of infective endocarditis. Effect of subinhibitory antibiotic concentrations on streptococcal adhesion in vitro and the development of endocarditis in rabbits. J Clin Invest 1981;68:1381-4

12. Perlman BB, Freedman LR. Experimental endocarditis. II. Staphylococcal infection of the aortic valve following placement of polyethylene catheter in the left side of the heart. Yale J Biol Med 1971;44:206-13

13. Pien FD, Williams RD, Vosti KL. Comparison of broth and human serum as the diluent in the serum bactericidal test. Antimicrob Agents Chemother 1975;7:113-4

14. Mandell GL, Vest TK. Killing of intraleukocytic Staphylococcus aureus by rifampin: in vitro and in vivo studies. J Infect Dis 1972;125:486-90 